\title{
Investigating Students' Adoption and Usage Behavior of Educational Technology(EduTech) at Tertiary Level (PLS-SEM Approach)
}

\author{
Md. Khaled Amin, Mohammad Arifur Rahman, Tahsina Khan, Mubasshir Tahmidul Karim
}

\begin{abstract}
This study sought to examine students' behavioral intention to use EduTech (Educational Technology) at the tertiary level education in Bangladesh. Using the unified theory of acceptance and use of technology (UTAUT) model as a base theory, the study attempted to explore the determinants that are swaying students' intention to adopt EduTech in Bangladesh. A total of one-hundred and forty-nine respondents were chosen randomly from three faculties of AIUB such as Business administration, Engineering and Science, were finally provided with the structured and self-administrated questionnaires followed by brief instructions to fill out the questionnaire. Moreover, collected data were encoded into SPSS for descriptive analysis such as demographic analysis, while SEM simulation, namely SMART PLS 2.0 was employed to analyze reliability and to test the hypotheses stated. Result of the study confirmed that the adoption and the usage behavior of EdTech at the tertiary level is highly influenced by Effort Expectancy, Facilitating Condition, and Perceived Behavioral Control. Findings of the study could be an important outline for educators, EduTech vendors, and service providers for formulating effective adoption strategies with regard to EduTech resources.
\end{abstract}

Keywords-Behavioral Intention, ICT, EduTech, E-learning, Usage Behavior;

\section{INTRODUCTION}

Due to the advancements of various technology and its associated products and services, students' learning patterns and behaviors have become unforeseen. Nowadays, learners prefer to study with PowerPoint slides rather than go through text, study in groups on Facebook rather than sitting physically in a

\section{Md Khaled Amin}

Department of Marketing

American International University -Bangladesh (AIUB)

Ka-66/1, Kuratoli Road, Kuril, Khilkhet, Dhaka 1229, Bangladesh

khaled.amin@aiub.edu,imran_mkt@yahoo.com

\section{Mohammad Arifur Rahman}

Department of Computer Science,

American International University -Bangladesh (AIUB),

Ka-66/1, Kuratoli Road, Kuril, Khilkhet, Dhaka 1229, Bangladesh, arif@aiub.edu

\section{Tahsina Khan}

Department of Marketing,

American International University -Bangladesh (AIUB),

Ka-66/1, Kuratoli Road, Kuril, Khilkhet, Dhaka 1229, Bangladesh. Email: tahsina@aiub.edu study area or library, take quizzes or exams online rather than in exam halls or classrooms, submit assignment online rather than in-person, contact with teacher online rather than to visit their office, etc. To meet this unprecedented demand, various Educational Technology (EduTech) resources have emerged and expanded their technical wings towards South East Asia in which EduTech is still regarded as an expensive and lack quality, though EdTech is playing a vital role in teaching and learning in higher education [1-3]. Unlike other countries, Bangladesh, which is still considered as the least developed country, is also experiencing a steady growth in this sector.

Furthermore, the government of Bangladesh has opened up various initiatives to enhance the use of technology to improve education [4]. As a result, numerous EduTech resources such as Digital Board, Moodle, Google-Class Room, Smart Printing Technology, Virtual desktop, education ERP, e-resources, educational websites, blogs have already been implemented and eventually has drawn the attention of both students and educators. In fact, EdTech can be defined as "the study and ethical practice of facilitating learning and improving performance by creating, using, and managing appropriate technological processes and resources' '[5]. Through the use of appropriate technology, students and educators can get connected and can utilize different types of study materials, which can be shared virtually.

However, this transformation has drawn limited attention by the scholars in academic research[6]. Nonetheless, it has been observed that to some extent students and educators are reluctant to incorporate these EduTech resources in their academic track, despite its versatile knowledge sharing features, and interactive graphical interface. Technology that improves productivity ought to accepted and used by the users and the study that describes the adoption behavior is regarded one of the most mature areas of study[7].Therefore, the research question of the study would be why and how a student adopts new information technologies in Bangladesh.

Using UTAUT[8] model as a base model, this study aims to examine Bangladeshi students' behavioral intention to adopt EduTech resources in tertiary level. Initially, all samples were taken from American International University-Bangladesh (AIUB), which was declared as a case study. Since its inception, AIUB has successfully initiated various EduTech resources; smart printing services, virtual desktop based PC, Wi-Fi network, RFID based multipurpose identity card, and a uniquely

Mubasshir Tahmidul Karim

Department of Electrical Engineering and Computer Science,

1845 Fairmount St. Wichita, Kansas 67260, USA.

Email: mubasshirkarim96@gmail.com 
designed platform namely, VUES which is considered as elearning module/platform available for the students and educators in order to facilitate academic activities.

\section{REVIEW OF RELATEd Literature AND STUdies}

\section{A. EduTech in Higher Education:}

Education Technology (also known as "EduTech" or "EdTech" can be defined as the appropriate use of technology in enhancing learning and improving performance[9]. Teacher inventiveness mostly relies on educational technology[10], as such EduTech needs to be implemented within a strategically developed framework that embraces a clear and unified vision[11]. The impact of ICT in higher education has been studied by the author highlighting the various impact of ICT on higher education and exploring potential future development[1]. The changing role of ICT in the work of teacher has been observed by the scholars in this field and found that ICT has been adopted by the majority of the teaching staff and serving as a teaching tool to support and improve day to day activities[12].The opportunities and challenges posed by the integration of ICT in higher education have been addressed by another author [13]. The effectiveness of the various web- based learning environments has been measured by the author and stated that through the integration of ICT, a rich learning experience can be fostered and positive learning outcome can be attained[14].

\section{B. UTAUT model in explaining EduTech Adoption}

Infrastructure plays a crucial role in promoting ICT aided teaching for schools [15]. The usefulness of blogs and wikis have been studied with regard to TAM constructs and found to have a positive relationship among these constructs[16]. Authors [17] extended the UTAUT model by introducing a construct, namely subjective task. The result suggested a positive effect on stimulating learners' intention in using web-based learning. Authors [18] examined the level of acceptance of Learning Management System in which a group of students were surveyed by using scales of UTAUT. Studies confirmed the usefulness of LMS in terms learning and teaching in tertiary level of education.

\section{Classical Technology Adoption Theories:}

For the past couple of decades, multidisciplinary studies have been undertaken to find out why and how an individual adopts and uses technology, in this vein a series of models, each with different types of variables have been yielded[19]. So far, various constructs have been identified, combined and empirically validated as models that describe the adoption behavior of various technology. In fact, the radical theory that explains the adoption behavior an individuals is known as the Theory of Planned Behavior (TPB) which had been extended and converted to TRA by adding a construct, namely perceived behavioral control [20]. Theory of Reasoned Action(TRA) had been used to predict a wide range of adoption behaviors[21]. In the year 1989, TRA had been improvised and extended to Technology Acceptance Model (TAM) along with its others extended versions known as TAM 2 and TAM 3[22]. Motivational Model (MM) had been applied to know the adoption behavior of new technology in 1992[22]. Theory of human behavior was refined and introduced as Model of PC Utilization(MPCU) with six constructs[22]. TPB and TAM were combined and renamed as C -TAM-TPB in 1995. UTAUT model which was initially formulated by a well-known scholar in this filed, with four core determinants of intention and usage, and four moderators that moderate the relationship between dependent and independent variables. The model itself explains up to $70 \%$ of the variance which is quite high compared to previous eight models in this field. Thus, it is the most useful tool for the managers to assess the likelihood of understanding behavioral intention in order to respond proactively [23], therefore, chosen as a base model for the study.

\section{Methodology}

This study simply adopted snapshot research approach in which all samples were collected within the stipulated time period on the premise of American International UniversityBangladesh (AIUB) (conducted between March 2017 and April 2017). A total of one-hundred and forty-nine respondents were chosen randomly from three faculties such as Business Administration, Engineering and Science of AIUB who were finally provided with the structured and self-administrated questionnaires. At the initial stage, all chosen respondents were briefed in a classroom environment about the usefulness and appropriateness of various EduTech resources on which they are currently embedded in. All Respondents were approached to fill out the self-administrated questionnaire measuring their responses on a seven-point Likert scale[24] ranging from Strongly Disagree (SD) to Strongly Agree (SA). Items used in this study were primarily adopted from prior studies related to UTAUT developed by Venkatesh. Collected data were initially encoded into SPSS for descriptive study, then encoded into SEM simulator for Confirmatory Factor Analysis (CFA).

\section{Research Design}

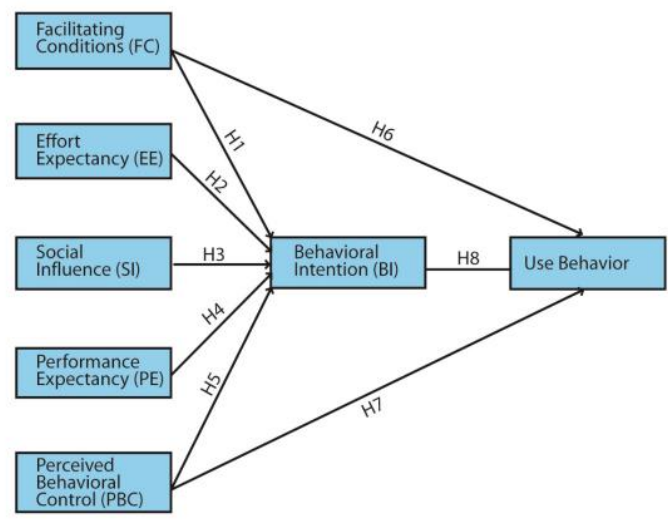

Fig. 1. Research Model:

Source: Venkatesh et al. (2003)

Figure 1 shows the research model of the study needs to be tested and validated in Bangladesh. The research model of the study has been derived from the original UTAUT model proposed by V. Venkatesh in 2003. A construct namely, Perceived Behavioral Control (PBC) has been added to the original model as a new construct in order to explore the current phenomena in Bangladesh. In this model, there are seven constructs that are connected with arrows forming causal relationships between latent variables, two of which are considered as endogenous variables and rest are regarded as exogenous variables. The arrows forming causal relationships among all latent variables. All moderators have been eliminated so as to simplify the model. 


\section{1) Hypotheses}

Based on the literature discussed above this study proposed the following hypotheses to be analyzed:

H1: There will be a significant positive relationship between $\mathrm{PE}$ and $\mathrm{BI}$ in Bangladesh.

$\mathrm{H} 2$ : EE will have a significant positive impact on BI.

H3: BI will be influenced significantly by SI.

H4: FC and BI will be positively correlated.

$\mathrm{H} 5$ : PBC will have a significant positive influence on BI.

H6: Use behavior will be positively influenced by PE

H7: There will be a significant positive relationship between $\mathrm{PBC}$ and Use Behavior.

H8: BI and Use Behavior are positively correlated.

\section{2) Structural Equation}

The following equations have been derived from the research model depicted in figure 1.

1. $\mathrm{BI}=\gamma 11 \mathrm{PE}+\gamma 12 \mathrm{EE}+\gamma 13 \mathrm{SI}+\gamma 14 \mathrm{FC}+\gamma 15 \mathrm{PBC}+\epsilon 1$

2. Use Behavior $=\beta 21 \mathrm{BI}+\gamma 21 \mathrm{PE}+\gamma 25 \mathrm{PBC}+\epsilon 2$

\section{Notes:}

$$
\begin{aligned}
& \gamma=\text { Gamma } \\
& \beta=\text { Beta } \\
& \epsilon=\text { Epsilon }
\end{aligned}
$$

$\mathrm{PE}=$ Performance Expectancy

$\mathrm{EE}=$ Effort Expectancy

$\mathrm{SI}=$ Social Influence

$\mathrm{FC}=$ Facilitating Conditions

$\mathrm{PBC}=$ Perceived Behavioral Control

$\mathrm{BI}=$ Behavioral Intention

\section{CFA RESUlT}

\section{A. Demographics of the respondents}

Respondents of the study are mainly students, more than $94 \%$ of them are studying the bachelor degree in three departments such as Business (66.6\%), Engineering (19.5\%) and Science $(14.1 \%)$. In addition, over $77 \%$ of them are male students and the rest of them are female students. Moreover, more than $95 \%$ of the respondents are aged between 20 to 29 years old. Furthermore, the computer and internet literacy of the majority of the respondents was ranked as "good".

\section{B. Reliability and Validity Analysis}

TABLE I. RELIABILITY AND VALIDITY

\begin{tabular}{|l|l|l|l|l|l|}
\hline & AVE & CR & $\mathbf{R}^{\mathbf{2}}$ & Cronbach's Alpha & No. of Items \\
\hline BI & $\mathbf{0 . 5 5}$ & $\mathbf{0 . 8 5}$ & 0.57 & $\mathbf{0 . 7 8}$ & 5 \\
\hline EE & $\mathbf{0 . 5 6}$ & $\mathbf{0 . 8 3}$ & & $\mathbf{0 . 7 4}$ & 4 \\
\hline FC & $\mathbf{0 . 5 3}$ & $\mathbf{0 . 7 7}$ & & $\mathbf{0 . 7 7}$ & 3 \\
\hline PBC & $\mathbf{0 . 6 4}$ & $\mathbf{0 . 8 4}$ & & $\mathbf{0 . 7 2}$ & 3 \\
\hline PE & $\mathbf{0 . 5 9}$ & $\mathbf{0 . 8 5}$ & & $\mathbf{0 . 7 6}$ & 4 \\
\hline SI & $\mathbf{0 . 6 0}$ & $\mathbf{0 . 8 2}$ & & $\mathbf{0 . 7 1}$ & 3 \\
\hline
\end{tabular}

\begin{tabular}{|l|l|l|l|l|l|}
\hline UB & $\mathbf{0 . 6 2}$ & $\mathbf{0 . 8 3}$ & 0.48 & $\mathbf{0 . 7 9}$ & 3 \\
\hline
\end{tabular}

A reliability analysis for the scales used in this study was conducted by applying the three standard criteria such as

Source: Estimated result

Cronbach's Alpha, AVE and CR. As shown in table 1, it can be seen that the all the Cronbach's Alpha values are adequate [25], In addition, all (Average variance Extracted) AVE values are above standard cut point [26]. Furthermore, it can also be seen that the $\mathrm{CR}$ (Composite Reliability) values are above the standard level [27]. Based on the result observed, it can be posited that all calculated values indicate a good internal consistency of the scales used in the study.

\section{Analysis of the Structural Model}

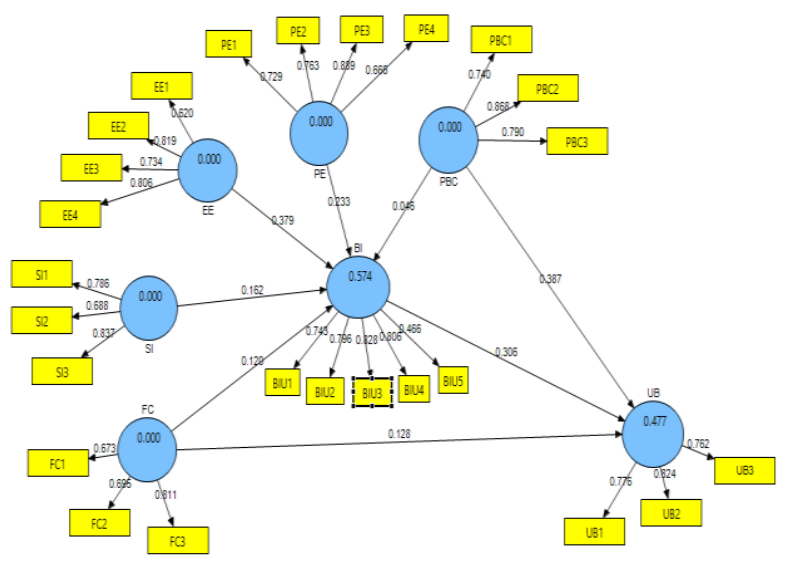

Fig. 2. Structural Model

\section{Source: Simulation Output}

The model (i.e., fig 2) comprising two endogenous and five exogenous variables. All outer loadings are quite adequate since all loadings exceeded the standard level. As shown in figure2, all endogenous variables are outlining the value of $\mathrm{R}^{2}$ that represents the amount of variance explained by others endogenous and exogenous variables. the study predicts $47 \%$ of the variance in UB from $\mathrm{PBC}, \mathrm{BI}$ and $\mathrm{FC}$. In addition, 57\% of the variance in $\mathrm{BI}$ is explained by $\mathrm{PBC}, \mathrm{PE}, \mathrm{EE}, \mathrm{SI}$ and $\mathrm{FC}$.

\section{Correlation Analysis}

TABLE II. CORRELATION ANALYSIS OF LVS

\begin{tabular}{|l|l|l|l|l|l|l|l|}
\hline & \multicolumn{1}{|c|}{ BI } & EE & FC & PBC & PE & SI & UB \\
\hline BI & 1 & & & & & & \\
\hline EE & $\mathbf{0 . 6 9}$ & 1 & & & & & \\
\hline FC & $\mathbf{0 . 5 0}$ & 0.47 & 1 & & & & \\
\hline PBC & $\mathbf{0 . 5 4}$ & 0.59 & 0.52 & 1 & & & \\
\hline PE & $\mathbf{0 . 6 4}$ & 0.72 & 0.44 & 0.50 & 1 & & \\
\hline SI & $\mathbf{0 . 4 8}$ & 0.38 & 0.46 & 0.56 & 0.38 & 1 & \\
\hline UB & $\mathbf{0 . 5 8}$ & 0.49 & 0.48 & $\mathbf{0 . 6 2}$ & $\mathbf{0 . 5 1}$ & 0.48 & 1 \\
\hline
\end{tabular}

Source: Estimated Result 
Table II shows a summary of all correlations of the latent variables used in this study. It appears that significant positive relationships were found among all latent variables. However, the strengths of the five relationships were "moderate" and the rest were "strong". To determine the impact of the independent variables on dependent variables along with the effect size, we, therefore, calculated the t-statistics and path coefficients

\section{E. Tests of Statistical Significance}

TABLE III. PATH COEFFICIENT AND HYPOTHESES

\begin{tabular}{|l|l|l|l|l|}
\hline $\begin{array}{c}\text { Hypothesized } \\
\text { Paths }\end{array}$ & $\begin{array}{c}\text { Coefficient } \\
(\boldsymbol{\beta})\end{array}$ & \multicolumn{1}{|c|}{$\begin{array}{c}\text { Standard } \\
\text { Error (S) }\end{array}$} & $\begin{array}{c}\text { T } \\
\text { Value }\end{array}$ & \multicolumn{1}{|c|}{ Result } \\
\hline BI =>UB (H8) & 0.31 & 0.0870 & 3.5166 & Supported \\
\hline EE =>BI (H2) & 0.38 & 0.1020 & 3.7184 & Supported \\
\hline FC =>BI (H1) & 0.12 & 0.0681 & 1.7650 & $\begin{array}{l}\text { Not } \\
\text { Supported }\end{array}$ \\
\hline FC =>UB (H6) & 0.13 & 0.0638 & 2.0031 & Supported \\
\hline PBC =>BI (H5) & 0.05 & 0.0794 & 0.5857 & $\begin{array}{l}\text { Not } \\
\text { Supported }\end{array}$ \\
\hline PBC =>UB (H7) & 0.39 & 0.0928 & 4.1687 & Supported \\
\hline PE =>BI (H4) & 0.23 & 0.1037 & 1.7444 & $\begin{array}{l}\text { Not } \\
\text { Supported }\end{array}$ \\
\hline SI =>BI (H3) & 0.16 & 0.0936 & 1.7276 & $\begin{array}{l}\text { Not } \\
\text { Supported }\end{array}$ \\
\hline
\end{tabular}

Source: Estimated Result

To calculate the t-statistics of the hypothesized paths, we simple run Bootstrapping which is also declared as a nonparametric approach [28]. Table 3 illustrates the test result of all hypotheses stated in the earlier part of this article. A total of eight hypothesized paths were analyzed using SEM simulator, five of which were statistically significant since all calculated $t$ values were above the standard cut point, and three of which were not statistically significant due to not exceeding the minimum value of 1.96 ( $\alpha=0.05$ for two-tailed test).

\section{DISCUSSION}

It has been well documented that the use of ICTs in any level of education is highly desired in order to achieve learning objectives and smoothen the learning process [29]. Estimated results of the study clearly support that the usage behavior (UB) of education technologies is highly influenced by three determinants such as PBC, BI and FC. PBC found to have a direct significant impact on usage behavior $(\beta=0.39, t=4.1687$, $\mathrm{P}<0.05)$. In addition, $\mathrm{FC}$ had a direct positive effect on $\mathrm{UB}(\beta=$ $0.13, \mathrm{t}=2.0031, \mathrm{P}<0.05)$. Contrary, Behavioral intention to use EduTech in Bangladesh is highly influenced by effort expectancy $(\beta=0.38, t=3.7184, \mathrm{P}<0.05)$.

\section{CONClusion AND Future RESEARCH DiRECTION}

In this paper, 1. We reviewed the existing literature of IT/IS adoption theories, 2. Applied UTAUT model in Bangladesh and empirically validated the model by incorporating a determinant, namely perceived behavioral control(PBC) with the original model. Result confirmed that EE significantly predicted $\mathrm{BI}$ while FC and PBC significantly predicted UB of a system in Bangladesh. This results of the study are quite similar to previous studies conducted by the authors [19, 30].This study can further be extended by incorporating variables such as system quality[31] and Information quality [32] in the context of Bangladesh

\section{REFERENCES}

[1] R. Oliver, "The role of ICT in higher education for the 21 st century: ICT as a change agent for education," Retrieved April, vol. 14, p. 2007, 2002.

[2] S. Sarkar, "The role of information and communication technology (ICT) in higher education for the 21st century," Science, vol. 1, pp. 30-41, 2012.

[3] B. Stensaker, xf, rn, P. Maassen, M. Borgan, M. Oftebro, et al., "Use, Updating and Integration of ICT in Higher Education: Linking Purpose, People and Pedagogy," Higher Education, vol. 54, pp. 417-433, 2007.

[4] M. T. Islam and A. S. M. Selim, "Current status and prospects for elearning in the promotion of distance education in Bangladesh," Turkish Online Journal of Distance Education, vol. 7, 2006.

[5] R. A. Reiser and J. V. Dempsey, Trends and issues in instructional design and technology: Pearson Boston, MA, 2012.

[6] M. Amin, A. Azhar, and A. Akter, "Factors Affecting Private University Students' Intention To Adopt E-Learning System in Bangladesh," 2016.

[7] P. J. Hu, P. Y. Chau, O. R. L. Sheng, and K. Y. Tam, "Examining the technology acceptance model using physician acceptance of telemedicine technology," Journal of management information systems, vol. 16, pp. 91 $112,1999$.

[8] Venkatesh, M. G. Morris, G. B. Davis, and F. D. Davis, "User Acceptance of Information Technology: Toward a Unified View," MIS Quarterly, vol. 27, pp. 425-478, 2003.

[9] A. Januszewski and M. Molenda, Educational technology: A definition with commentary: Routledge, 2013.

[10] M. Guzdial, J. Rick, and C. Kehoe, "Beyond adoption to invention: Teacher-created collaborative activities in higher education," The Journal of the Learning Sciences, vol. 10, pp. 265-279, 2001.

[11] D. McCann, J. Christmass, P. Nicholson, and J. Stuparich, "Educational technology in higher education," Canberra. Department of Employment, Education, Training and Youth Affairs, 1998.

[12] G. Kirkup and A. Kirkwood, "Information and communications technologies (ICT) in higher education teaching - a tale of gradualism rather than revolution," Learning, Media and Technology, vol. 30, pp. 185-199, 2005.

[13] M. CHELlADURAI and S. PITCHAMMAL, "ICT in Higher Education," Copyright@ 2016 by HINDCO Publications, Tirunelveli627010, p. 80, 2016.

[14] L. Lockyer, J. Patterson, and B. Harper, "ICT in higher education: Evaluating outcomes for health education," Journal of Computer Assisted Learning, vol. 17, pp. 275-283, 2001.

[15] L. Chun, T. Chin-Chung, and W. Di, "The Role of ICT Infrastructure in Its Application to Classrooms: A Large Scale Survey for Middle and Primary Schools in China," Journal of Educational Technology \& Society, vol. 18, pp. 249-261, 2015.

[16] A. Ummuhan and A. Petek, "The Comparison of the Opinions of the University Students on the Usage of Blog and Wiki for Their Courses," Journal of Educational Technology \& Society, vol. 15, pp. 194-205, 2012.

[17] C.-M. Chiu and E. T. Wang, "Understanding Web-based learning continuance intention: The role of subjective task value," Information \& Management, vol. 45, pp. 194-201, 2008.

[18] A. Raman, Y. Don, R. Khalid, and M. Rizuan, "Usage of learning management system (Moodle) among postgraduate students: UTAUT model," Asian Social Science, vol. 10, p. 186, 2014.

[19] M. M. Groves and P. C. Zemel, "Instructional technology adoption in higher education: An action research case study," International Journal of Instructional Media, vol. 27, p. 57, 2000.

[20] I. Ajzen, "From intentions to actions: A theory of planned behavior," in Action control, ed: Springer, 1985, pp. 11-39.

[21] M. Fishbein, "A theory of reasoned action: some applications and implications," 1979.

[22] V. Venkatesh and F. D. Davis, "A theoretical extension of the technology acceptance model: Four longitudinal field studies," Management science, vol. 46, pp. 186-204, 2000.

[23] V. Venkatesh, M. G. Morris, G. B. Davis, and F. D. Davis, "User acceptance of information technology: Toward a unified view," MIS quarterly, pp. 425-478, 2003.

[24] R. Likert, "A technique for the measurement of attitudes," Archives of psychology, 1932.

[25] J. A. Gliem and R. R. Gliem, "Calculating, interpreting, and reporting Cronbach's alpha reliability coefficient for Likert-type scales," 2003. 
[26] C. Fornell and D. F. Larcker, "Evaluating structural equation models with unobservable variables and measurement error," Journal of marketing research, pp. 39-50, 1981.

[27] J. Henseler, C. M. Ringle, and R. R. Sinkovics, "The use of partial least squares path modeling in international marketing," in New challenges to international marketing, ed: Emerald Group Publishing Limited, 2009, pp. 277-319.

[28] J. F. Hair, W. C. Black, B. J. Babin, R. E. Anderson, and R. L. Tatham, Multivariate data analysis vol. 5: Prentice hall Upper Saddle River, NJ, 1998.

[29] Z. Sidiq, "PERCEPTIONS OF ELEMENTARY SPECIAL SCHOOL TEACHERS ON ICT BASED INSTRUCTIONAL MEDIA IN FACILITATING CHILDREN WITH SPECIAL NEEDS IN LEARNING IN MAJALAYA DISCTRICT BANDUNG REGENCY," Edutech, vol. 14, pp. 142-150, 2015.

[30] S. N. Attuquayefio and H. Addo, "Using the UTAUT model to analyze students' ICT adoption," International Journal of Education and Development using Information and Communication Technology, vol. 10, p. 75, 2014 .

[31] [31] R. R. Nelson, P. A. Todd, and B. H. Wixom, "Antecedents of information and system quality: an empirical examination within the context of data warehousing," Journal of management information systems, vol. 21, pp. 199-235, 2005.

[32] [32] S. Titman and B. Trueman, "Information quality and the valuation of new issues," Journal of accounting and economics, vol. 8, pp. 159-172, 1986.

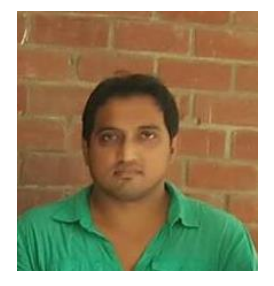

Md. Khaled Amin is an Assistant Professor of Marketing in the Faculty of Business Administration at American International University-Bangladesh (AIUB). Before joining AIUB, Mr. Amin worked as a Senior Lecturer for Daffodil International University (DIU) and as a Lecturer for Northern University Bangladesh (NUB). Besides, Mr. Amin also worked as a parttime faculty member for universities such as Zhejiang Shuren University, Zhejiang Gongshang

University (ZJSU), Uttara University(UU). He holds a Master Degree and a Bachelor Degree in Business Administration with concentration in Marketing from AIUB, and completed his Doctorate Degree in Management Science with concentration in Marketing and Innovation Management at Zhejiang Gongshang University(ZJSU), China. His academic research interest encompasses a broad spectrum of areas such as Consumer Psychology, E-commerce and Social Media, E-learning, Technology and Innovation. $\mathrm{He}$ is particularly concerned with the acceptance and the adoption of various ICTs driven products and services by the rural consumers in Bangladesh. He has published several research papers both in local and foreign journals and conferences. Aside from being a faculty member of AIUB, he has been serving as an active reviewer and editorial member for several journals and conferences, and actively participating in various conferences, workshops, and symposiums both in home and abroad.

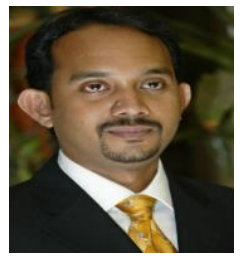

Mohammad Arifur Rahman completed his BSc in CIS at Minnesota State University, Mankato, USA, and later on pursued an MBA in Marketing from NSU. Mr. Rahman is currently working as a Lecturer in the Department of Computer Science at American International University-Bangladesh (AIUB). He has been with the IS/IT industry since 1994 working mostly on various technical and nontechnical positions. Mr. Rahman also worked

as IT consultant for National Life Insurance Company, Uttara Group, Aamra Networks, and Bangladesh Telecommunication Regulatory Commission (BTRC). He is primarily concerned with the issues related to various Web Solutions, but recently he is continued to take a keen interest in research and development in the field of Software Engineering.

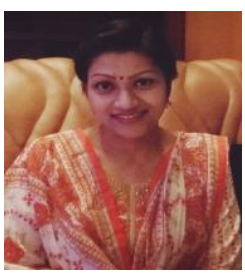

Tahsina Khan is serving as a Senior Assistant Professor in the Department of Marketing at American International University-Bangladesh (AIUB). She completed her Master Degree in Business Administration with concentration in Marketing, and completed her Bachelor degree in Business Administration with concentration in Finance and Accounting at AIUB. Besides, she has been actively involved in several department

projects such as outreach program, course curriculum and conten development for introducing new major courses which are initiated by AIUB and funded by Swiss-contact Katalyst. Her preferred research areas include services marketing, strategic marketing, and development studies. Currently she is working on multiple research projects including the distribution and adoption of renewable energy technology in the rural communities, and the prospect of internal branding in corporate sector of Bangladesh.

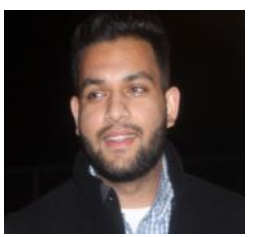

Mubasshir Tahmidul Karim is a Junior (thirdyear) student in the department of Electrical Engineering and Computer Science at Wichita State University(WSU), USA 
